\title{
In Defence of Cost-Benefit Analysis
}

\section{Henry Ergas ${ }^{1}$}

In this paper I compare cost-benefit analysis (CBA) to multi-criteria analysis (MCA). I review the nature of the two approaches and consider the criticisms that have been made of CBA. I conclude that these criticisms largely lack merit, and that even to the extent to which they are meritorious, they provide no justification for relying on MCA. I conclude by expressing my concerns about the growing role of MCA in Australian project appraisal, which is symptomatic of a broader move away from sound policy evaluation.

\section{CBA}

Cost-benefit analysis (CBA) is a technique for evaluating collective decisions that hinges on the comparisons of the costs of a proposal to its benefits, where costs and benefits are valued in monetary terms. In essence (and abstracting from the relevant technicalities), cost-benefit analysis asks whether the sum of the amounts the individuals who comprise the community at issue would be willing to pay for the project to proceed exceeds the costs of that project. Generally, a project enhances wealth - in the sense of the aggregate monetary valuation of the community's resources - if it meets a properly specified cost-benefit test. Whether enhancing wealth in this sense is either necessary or sufficient for a project to be worthwhile is a complex issue. Without going into the details of that discussion, it seems reasonable to suggest that projects that fail properly specified cost-benefit tests should be looked at very carefully, and be found to have other, significant, redeeming features, before they are allowed to proceed. By the same token, if a project has benefits that (evaluated in monetary terms) clearly exceed its costs, it seems reasonable to presume that, in the absence of compelling reasons to the contrary, society would gain were it to proceed.

Multi-criteria analysis (MCA), rather than seeking an overall monetary valuation of project effects, identifies salient elements of those effects (be they costs or benefits), scales them and then places subjective weights upon them. In that sense, it is a technique for scoring project attributes. The project is expected to be approved if the weighted sum of the desirable effects (that is, the scaled value of the various dimensions of project benefits) exceeds the weighted sum of the project's undesirable effects (the scaled value of its costs and harmful outcomes). Elsewhere in this issue, Dobes and Bennett provide a

\footnotetext{
${ }^{1}$ Concept Economics, henryergas@concepteconomics.com.au. I am very grateful to Alex Robson, Eric Ralph, an anonymous referee, Jonathan Pincus, Mark Harvey, William Coleman and, especially, Mark Harrison for many, very helpful comments and discussions. Responsibility for the views expressed here, and for any remaining errors, is of course entirely my own.
} 
worked, hypothetical, example of MCA as it is typically implemented in Australian policy evaluation.

\section{The differences between CBA and MCA}

There are, in my view, six critical differences between CBA and competitors to it such as MCA.

First, evaluative standpoint. There is a presumption in CBA that the value policy-makers place on a policy's effects ought to be derived from the valuations of the individuals who will bear those effects. ${ }^{2}$ It is for this reason that where a policy affects traded goods and services, the valuations used will be those captured in market prices (taking account of the fact that those prices may differ as between the world with and without the policy at issue), as market prices will reflect individuals' willingness to pay for benefits and their willingness to accept costs. ${ }^{3}$ Equally, it is this presumption that guides the methods used to correct market prices where they are distorted by taxes, subsidies or price controls, or to impute valuations where the policy's effects involve goods or services (or dimensions of goods or services) that are not traded.

Underlying this presumption is the belief that where a project is being evaluated by a collective agent on behalf of a group of individuals, that project should be adopted if those individuals' preferences are advanced by that decision, such that were those individuals taking the decision themselves, they would adopt the project at issue.

In that sense, there is a close link between CBA and an approach that gives individual preferences primacy in collective decision-making. This, in turn, creates a natural consistency between the use of CBA and the legitimacy of public action, where legitimacy is a matter of the extent to which decisions are rational, confer benefits on those on whose behalf they are being taken, and are based on actual or reasonably assumed consent.

The evaluative standpoint is far less clear in alternative approaches. Specifically, in MCA, the evaluative standpoint may (as Dobes and Bennett suggest) be that of the evaluator, who determines the relevant scores;

\footnotetext{
2 There are cases where those valuations are not accepted or are in some way over-ridden. For example, in assessing the costs and benefits of drug-control policies, the valuations of casual drug users and drug addicts are not given standing or, at least, are not weighted in the same way as other valuations. However, even here this 'over-riding' is explicit, and thus transparent to the analysis, which could be repeated allowing for the undiscounted preferences. In contrast, MCA approaches simply assert a set of values that can in no ready way be mapped back to individuals' desires. Different outcomes are obviously obtained with different values and value weightings, but the choice of these is ultimately arbitrary.

${ }^{3}$ The basic notion underpinning use of willingness to pay as a measure is that if a person did pay that amount (or, when the willingness to pay is negative, receive that amount), he or she would be no better or worse off with the project than without. To the extent the overall willingness to pay for a project exceeds its costs, society is better off by the amount of the surplus; that is, all individuals could be made at least as well off as they would be without the project, with something left over to make some better off.
} 
alternatively, there may be the claim that the scores are those of society as a whole, but it is not obvious whether or how they relate to, or are derived from, underlying individual valuations. Moreover, depending on how the scores are allocated, the results can be vulnerable to voting pathologies such as those associated with non-transitivity or with small differences in valuation leading to large differences in outcomes. ${ }^{4}$ The results cannot therefore be related back to underlying concepts of rational collective decision-making or of actual or implied legitimacy.

Second, decision-relevance. A project is wealth-increasing if its benefits exceed its costs (the 'total test'), including the opportunity cost of pursuing alternative projects or of pursuing that project on a different scale (the 'marginal test'). A properly constructed CBA captures this criterion because the weights it uses for the various dimensions of benefits and cost are commensurable and reflect incremental valuations, allowing it to aggregate benefits and costs, to treat as costs the net valuations forgone in pursuing that project relative to others, and to take account of the option (if there is one) of varying project scale. Moreover, commensurability extends to the time dimension, allowing the use of a discount rate to convert future consequences into present values and making it possible to evaluate alternative time profiles for a given project. Together, all of these features mean that CBA allows different projects (including the project of doing nothing or doing the proposed project on a different scale), and different options within any given project, to be evaluated and compared.

In contrast, the weights and scores used in MCA are not generally commensurable (and indeed are often manufactured by the stakeholders) and would only by accident measure rates of substitution in consumption or of transformation in production between the various dimensions of the project's impact. As well as undermining attempts to assess whether total and marginal tests are passed, this lack of commensurability means that it is difficult to see whether or how time-dated effects in a MCA evaluation can be consistently discounted.

Third, comparability. An advantage of the systematic use of CBA is that it allows consistent values to be used across projects for assessing particular project inputs or outcomes. For example, using a standard value for a statistical life can help ensure that social outlays aimed at saving lives are used efficiently; that is, through a project mix such that reallocating resources among projects would not increase lives saved for a given total outlay. ${ }^{5}$ Equally, using a common

\footnotetext{
4 There are multi-criteria decision-making procedures, such as ELECTRE, that seek to avoid these anomalies, albeit at the cost of seemingly arbitrary restrictions (for instance, on preference thresholds). ${ }^{5}$ For example, there is evidence that decisions taken by different US government agencies imply very different valuations of the cost of saving lives - see Tengs and Graham (1996: 167, 177). This has naturally focused attention on the scope for improving outcomes by shifting outlays from less cost-effective to more cost-effective life-saving programs.
} 
approach to setting the discount rate $^{6}$ is clearly necessary if meaningful project rankings are to be derived.

Although such consistency is not always achieved in practice, the structure of CBA naturally invites it, for two reasons: because inputs and outcomes can be defined in standard terms across projects and the weights placed upon them compared; and because the weights are generally separable, so that changing, for example, the discount rate, does not change the value of a life.

In contrast, in MCA, the weights themselves are rarely transparent, and because they are derived by looking at the project as a whole, it is not clear that they can be treated as separable in the sense defined above. As a result, the scores used in MCA evaluations cannot be given an interpretation that is independent of the projects themselves, nor can they be compared across projects, undermining the extent to which they can be used to improve the efficiency or cost-effectiveness with which goals (such as saving lives) are achieved.

Fourth, verifiability. The assumptions used in a CBA are capable of being tested in terms of their consistency with market valuations, the way in which market valuations have been altered, and the methods used to measure and weight non-marketed inputs and outputs. It is because of this verifiability that CBA can improve on the principal-agent problems that bedevil collective decision-making, just as the capacity to audit companies' financial reports allows shareholders and other input suppliers to improve on the principal-agent problems inherent in the modern corporation. However, it is difficult to see how the essentially subjective weights used in MCA are capable of third-party audit, so that while they may formalise the discretion exercised by the relevant decision-maker, they merely express, rather than constrain, that discretion.

Fifth, accountability. As CBA estimates impacts and costs and benefits in quantitative terms and lays out all of its underlying assumptions, it can be found to be wrong after the fact. It might turn out, for instance, that people value a new national park by less than was assumed by a study recommending its creation. In contrast, unless a CBA had actually been undertaken (in which case why do the MCA?), it is difficult to see how one could determine that an MCA assessment was wrong after the fact. This may be a reason why MCA is gaining popularity - as a device for reducing accountability for decisions.

Sixth and last (and stressed to me by an anonymous referee), scientific progression. CBA gets better over time because it attempts to systematically measure impacts and the values placed upon them and does so in a way that is comparable from study to study. These repeated attempts generate:

\footnotetext{
${ }^{6}$ Even with such a common approach, the discount rate used in different projects will of course differ depending on the risk characteristics of each project.
} 
- A body of quantitative techniques for measuring impacts with some degree of rigour;

- Better tools for understanding how people actually behave in the face of changes such as construction or improvement of transport facilities;

- Lessons from the falsification of specific types of past analysis (facilitated by and closely related to the virtue of accountability discussed above); and

- A body of evidence accumulated over time and across countries that can be used to calibrate future models better.

In contrast, the lack of accountability noted above makes comparable progression in MCA difficult or impossible.

\section{Criticisms of CBA}

While CBA trumps MCA in each of these respects, CBA has been subjected to a wide range of criticisms. I review three of the leading criticisms and consider whether they justify replacing CBA by MCA.

\section{Non-commensurability}

A first criticism is that CBA cannot deal with the non-commensurable dimensions of a policy or project evaluation, particularly those dimensions that cannot (or, for ethical reasons, should not) be given a monetary valuation.

There are indeed circumstances in which CBA cannot be a complete answer to the problem of policy or project evaluation. A project may have benefits that exceed its costs but be rejected on non-consequentialist grounds, for example, because it offends accepted moral standards. ${ }^{7}$ Alternatively, even putting deontological concerns aside, some dimensions of a project's effects may be more readily expressed in monetary form than others.

Even in those cases, however, monetizing the costs and benefits associated with those effects that are capable of being so valued can still provide a better basis for public decision-making than could occur in the absence of that quantification. This is because the decision then provides a de facto valuation, from the perspective of the public decision-maker, of those elements that are not capable of monetary valuation or are not appropriately valued on a monetary basis. For example, if the monetary benefits of a policy exceed its costs by some amount, then a decision by the public decision-maker not to proceed with that

\footnotetext{
7 "Consequentialism" refers to decision-making on the basis of an assessment of the consequences of choice. It is generally contrasted with "deontological" approaches, in which decisions are made on the basis of inherent values, rather than of a balancing of consequences. For example, most people would regard a prohibition on torture as being a matter of ethics, independently of whether it is capable of being justified by any kind of utilitarian or, more generally, consequentialist assessment. Decisions that have a strong ethical component can only be cast in monetary terms by means of artifices (such as imputing a very high 'cost' to breaching an ethical precept), which effectively over-ride the cost-benefit assessment as such.
} 
policy because of non-quantifiable costs implies that the harms associated with the non-quantifiable impacts at least outweigh the net benefits estimated for the quantifiable elements.

As a result, this criticism does little to undermine the relevance of properly conducted CBA. Rather, it may be one of CBA's strengths that it can focus attention on, and provide for explicit political resolution of, non-consequentialist aspects of policy-making. However, even if the criticism had more bite than it has, relying on it as a basis for replacing CBA by MCA would seem a case of throwing away the baby with the bathwater, as what is required is a process that, rather than ignoring the CBA, complements the information CBA yields with a social valuation of the non-monetized aspects of the project's effects.

\section{Income distribution}

A second criticism is that CBA treats a dollar as a dollar, regardless of who it is removed from, or accrues to. This gives a greater weight to higher-income consumers, who have a lower marginal utility of income and hence can 'pay more' to secure a benefit or avoid a loss. In that sense, aggregating willingness to pay involves an information loss, relative to a 'perfect' utility measure, due to differences in the marginal utility of income.

Where compensation is actually paid (in the sense that the 'winners' from a policy change compensate the 'losers' from that change), distributional consequences are of little relevance, as the compensation payment will ensure that those adversely affected are no worse off. ${ }^{8}$ In this case, relying on aggregate willingness to pay is obviously appropriate. However, compensation is often not provided for policy decisions, and hence the distribution of net benefits as between parties may be viewed as needing consideration in the policy evaluation process. ${ }^{9}$ However, the assumption that a dollar is a dollar implicitly sets these considerations aside or at least separates them from consideration of efficiency.

There are several cogent reasons for separating policy for income distribution from policy for wealth maximisation in the evaluation of policies that do not have explicitly redistributive goals. The first centres on efficiency. As a general matter, it is more efficient to redistribute income through explicit tax-transfer

\footnotetext{
8 There is the hypothetical case in which a policy only affects the rich, making them better off, while having no impact on the income of the poor. As a result, explicit compensation is irrelevant. Nonetheless, some might still object to the policy on the grounds that the poor would be relatively worse off, and hence should be compensated.

${ }^{9}$ Where costless lump-sum transfers are possible, then to determine whether there is a net benefit from a project, it suffices to ask whether implementing the project increases the government's budget balance in the compensated equilibrium (that is, where utilities are held fixed relative to the world without the project through offsetting lump-sum transfers). In that case, it is clear that all projects that yield a net gain in the budget balance are potential Pareto improvements. However, where lump-sum transfers are impossible (and in any event utilities themselves cannot be observed), the fact that a project would, on this measure, increase wealth should obviously be relevant to the decision-maker but may not be determinative.
} 
policies than through instruments such as infrastructure policies, environmental programs or health-and-safety regulations. ${ }^{10}$ The fact that the ultimate incidence and distributional consequences of these instruments are often extremely unclear makes this relative-efficiency argument all the stronger. ${ }^{11}$ Kenneth Boulding's poetic injunction, apropos claims that income distribution issues should be considered in assessing the California Water Plan, comes to mind:

It would be well to be quite sure

Just who are the deserving poor,

Or else the state-supported ditch

May serve the undeserving rich

(Boulding 1966).

Second, although one could give greater or lesser value to benefits depending on who they accrue to (and symmetrically for costs), it is unclear how the evaluator would determine the weights to be used and attempts to do so are largely arbitrary. Ultimately, we cannot measure 'utilities', much less determine the correct social-welfare function, and it is foolish to pretend otherwise. Rather, there is, here, an element that is essentially political, and which is best left to the political system, while leaving to project evaluation the feasible, verifiable and still highly relevant task of assessing impacts on wealth.

Lastly, it can be argued that it is the overall impact of public projects - that is, the impact of the portfolio of projects taken as a whole - that we should be concerned with in considering issues of income distribution, for it is that overall impact that determines the pattern of gains and losses that explicit redistributive interventions might then want to correct. Seen in that light, it is reasonable to think that (putting aside programs specifically aimed at redistribution) those overall impacts are widely distributed in the community, so that the distributional consequences of individual programs roughly cancel out in the 'swings and roundabouts'.

A policy of adopting projects that have monetary benefits that exceed their costs will thus tend to make all individuals better off, as well as providing efficiency gains that can fund programs that address serious disadvantage. To that extent, with all individuals gaining from the project portfolio, differences in the marginal utility of income will only affect the aggregate extent of the net

\footnotetext{
10 The theory of optimal taxation shows that there are circumstances in which it is efficient to use instruments other than tax-transfer policies to redistribute income. Generally, these circumstances involve cases in which the instruments allow transfers to be made to low income consumers with very little leakage to high income consumers. For example, subsidising milk in schools may effect a significant benefit to low income consumers with little loss of incentive or effort by high income households. That said, it is not clear that such cases arise with respect to the types of issues involved in the evaluation of infrastructure projects or of other programs that do not have income redistribution as their primary objective.

11 For example, gains in user surplus as captured in the traditional Dupuit measure of the benefits from a transport program may ultimately be capitalised in land values, and hence accrue to land-owners.
} 
gain from the portfolio of programs but not its sign. Moreover, even were it not the case that all individuals gain from the overall project portfolio, if both the 'winners' and the 'losers' are large and diverse groups, such that the marginal utility of income does not vary systematically between them, then projects that increase net wealth will likely also be utility increasing.

These arguments notwithstanding, there is, as Dobes and Bennett note, no reason in principle why distributional weights cannot be used in valuing costs and benefits of decisions. But using such weights introduces (for reasons noted above) an element of arbitrariness into CBA that moves it closer to MCA. If distributional issues are to be considered, it is better to do so by separately identifying the distributional consequences of particular projects and allowing those consequences to be an element in the final decision alongside the standard estimate of project net benefits.

As a result, the criticism of $\mathrm{CBA}$ on grounds of income distribution is not particularly telling; and even to the extent to which it does have bite, it hardly seems to justify replacing CBA by MCA.

\section{Accuracy}

The third and final criticism of CBA considered here is that it is based on complex assumptions, and hence likely to be inaccurate. While this is correct, it merely reflects the difficulty inherent in assessing and valuing the effects of public projects. To that extent, it is not an argument against CBA; rather, it is an argument against public projects. Even less is it an argument for replacing CBA by MCA: there is no reason whatsoever to think that MCA is any more accurate than CBA. Indeed, as noted above, the valuation weights and assumptions used in CBA are capable of being compared across projects, and as between initial projections and out-turns; neither of these can be done in MCA. As a result, use of MCA is more likely to undermine accuracy in project appraisal than to advance it.

\section{The current state of Australian project evaluation}

Set against this background, there are grounds for being extremely concerned about the state of project evaluation in Australia. For example, a recent advocacy of MCA can be found in Infrastructure Australia's guide to project evaluation, which says that funding applications will be assessed based on a 'triple bottom line' approach that also takes account of projects' 'strategic fit', seeks the 'efficient use of existing infrastructure and resources' while 'optimising the role of both the public and private sector'. However, CBA has always considered relevant environmental and social impacts in assessing project net benefits; to consider them twice, as occurs in 'triple bottom line' evaluations where projects are ranked both on the results of a CBA and on environmental and social grounds, is simply double counting. Confusion in this respect merely highlights the extent to which 
these increasingly popular 'triple bottom line' evaluations lack analytical rigour and seem aimed at maximising the discretion left to the decision-maker, creating room not merely for error, but also for rent-seeking (see Ergas 2009). This is, of course, the antithesis of proper cost-benefit appraisal.

That said, it is unfortunately impossible to know whether actual project evaluations are indeed as poor as the Infrastructure Australia report could lead one to fear. In effect, although it has allocated billions of taxpayer dollars to infrastructure decisions, the current Commonwealth government has decided not to release the evaluations on which those decisions are based, claiming that these are 'commercial in confidence'. As well as limiting the contribution which evaluation can make to the accountability and legitimacy of public decision-making, this ensures that the public is in no position to assess whether the project-evaluation methods used meet reasonable professional standards.

In its 2008-09 Budget, the government promised 'decision-making based on rigorous cost-benefit analysis to ensure the highest economic and social benefits to the nation over the long term' (Commonwealth of Australia 2008: 14-5). However, the degree to which this promise has been respected is questionable, as demonstrated by the government's commitment, on 7 April 2009, to fund a National Broadband Network whose deployment is estimated to cost $\$ 43$ billion.

Thus, according to a report in Communications Day of 13 May 2009, the Communications Minister, Senator Stephen Conroy, when asked by the Opposition whether a cost-benefit study had been carried out of the proposed expenditure, said there was 'no need' for such a study, as 'Labor's commitment to build a high-speed broadband network has been clear ... A range of studies have been carried out all over the world that have investigated the economic impact of broadband.'

The Finance Minister, Lindsay Tanner, who has responsibility for promoting cost-benefit evaluation in the Commonwealth government, then confirmed that no cost-benefit study had been carried out and that none was envisaged, because 'We just formed the view that in effect we had to make the clear decision that said this is the outcome we are going to achieve come hell or high water because it is of fundamental importance to the future of the Australian economy" (Bartholomeusz 2009).

These views bring to mind the French politician cited by David Henderson (1986) in his masterly analysis of 'Do It Yourself Economics', who believed that agriculture was too important to be subjected to appraisal of costs and benefits: the object of the cargo cult may have evolved with the times - broadband replacing dairy cows - but the logic, if it can be called that, is the same.

This suggests that the problems go well beyond the technical issues of how MCA compares with CBA, important though those are: rather, they go to the 
basic issue of whether policy decisions are based on rational, transparent, criteria or on instincts, diktats and deals. Dobes and Bennett's defence of the use of CBA is therefore all the more timely and important.

\section{References}

Bartholomeusz, S. 2009, 'Conroy's stab in the dark', The Business Spectator, 15 May.

Boulding, K. 1966, 'The Feather River anthology', Industrial Water Engineering 3(12): 32-3.

Commonwealth of Australia 2008, 2008-09 Budget Paper No. 1, Statement 4: Boosting Australia's Productive Capacity: the Role of Infrastructure and Skills.

Ergas, H. 2009, 'Infrastructure Australia, A report to the Council of Australian Governments', Agenda 16(1): 79-82.

Henderson, D. 1986, Innocence and Design: the Influence of Economic Ideas on Policy, Oxford, UK: Blackwell.

Tengs, T. and Graham, J. D. 1996, 'The opportunity costs of haphazard social investments in life saving', in R. W. Hahn (ed.), Risks, Costs, and Lives Saved: Getting Better Results from Regulation, Oxford University Press, New York; AEI Press, Washington, D.C. 